\title{
GESTÃO E MUDANÇAS NA AMPLITUDE DE COMANDO: UM ESTUDO NO SETOR INDUSTRIAL EM MONTES CLAROS-MG, MINAS GERAIS E BRASIL
}

\author{
Roney Versiani Sindeaux ${ }^{1}$, Hércules Antunes Soares ${ }^{2}$ \\ e Jamille Alves Martins ${ }^{3}$
}

\begin{abstract}
RESUMO
As mudanças nos conceitos e práticas de gestão nas empresas provocam também alterações na estrutura organizacional, principalmente na amplitude de comando, ou seja, no número de subordinados sob o controle de um superior. Este é o foco do trabalho. 0 objetivo é analisar tal característica no setor industrial para o Brasil, o Estado de Minas Gerais e 0 município de Montes Claros-MG. A partir da base de dados da RAIS/MTE, observou-se 0 comportamento do número de superiores e subordinados das organizações no período de 1985 a 2011 e, numa perspectiva descritiva, foram comparados esses números e a relação entre eles. Os resultados demonstraram que, se por um lado não houve significante mudança na amplitude de comando no que diz respeito à relação entre Diretores-Gerentes, por outro lado, a relação Gerentes-Subordinados apresentou um crescimento considerável. Tal aspecto reforça a perspectiva de que a estrutura organizacional está mais achatada, com maior amplitude de comando dos gerentes, embora nos níveis mais elevados isso não se confirmou. A análise destacou ainda as diferenças nos indicadores para Brasil, Minas Gerais e Montes Claros, buscando apontar, ainda que preliminarmente, a importância das características regionais na definição da estrutura organizacional das empresas.
\end{abstract}

Palavras-chave: Amplitude de comando. Gestão. Indústria. Estruturas organizacionais.

\footnotetext{
${ }^{1}$ Professor Doutor do Departamento de Ciências da Administração da Universidade Estadual de Montes Claros - Unimontes, Brasil. roneyvs@yahoo.com.br

${ }^{2}$ Graduando em Administração e Bolsista de Iniciação Científica do projeto Observatório do Trabalho no Norte de Minas. Financiado pela Fapemig, Brasil. herculesmajestade@hotmail.com

${ }^{3}$ Graduando em Administração e Bolsista de Iniciação Científica do projeto Observatório do Trabalho no Norte de Minas. Financiado pela Fapemig, Brasil. gepad@unimontes.br
} 


\title{
MANAGEMENT AND CHANGES IN THE COMMAND RANGE: A STUDY IN THE INDUSTRIAL SECTOR IN MONTES CLAROS - MG, MINAS GERAIS AND BRAZIL
}

\begin{abstract}
Changes in management concepts and practices in companies also bring on changes in the organizational structure, mainly in the amplitude of command, that is, the number of subordinates under the control of a manager. This is the focus of this article. The aim is to analyze such feature in the industrial sector in Brazil, the state of Minas Gerais and the city of Montes Claros-MG. From the database of RAIS/MTE, we observed the behavior of the number of superiors and subordinates in the companies in the period between 1985 and 2011, and, in a descriptive perspective, we compared these numbers and the relationship between them. The results showed that, while there was no significant change in the command range regarding the president-managers relationship, the managers-subordinates relationship has grown considerably. This reinforces the idea that the organizational structure is flatter, with greater range of managers' command, although at higher levels this was not confirmed. The analysis also highlighted the differences in the indicators for Brazil, Minas Gerais and Montes Claros, trying to point out, albeit preliminarily, the importance of regional characteristics in defining the organizational structure of the companies.
\end{abstract}

Keywords: Range of command. Management. Industry. Organizational structures.

\section{INTRODUÇÃO}

$\mathrm{D}$ esde sua origem a partir da Revolução Industrial e do modo capitalista de produção, a gestão se fundamenta no controle. Essa é a tônica deste artigo. Mais precisamente, uma análise sobre as mudanças na relação entre o número de subordinados por gestor, denominado aqui, livremente, de amplitude de comando.

Para tal análise, buscou-se, além de vincular a origem da gerência ao controle, recuperar a perspectiva Taylorista de múltipla supervisão ou "supervisão funcional", passando pelo ponto de vista de Fayol da "unidade de comando" para, em seguida, proceder a uma breve discussão sobre as mudanças nas organizações, destacando as transformações que têm influenciado a estrutura das empresas e, segundo Dewitt (1993 apud MENDONÇA; VIEIRA, 1999), conduzindo a uma tendência de achatamento das estruturas hierárquicas, com um enxugamento (downsizing) em busca de maior eficiência organizacional. 
Nessa perspectiva, haveria então um alargamento da amplitude de comando, com os níveis de gestão controlando um número maior de subordinados a partir dessas mudanças. Será que isso ocorreu nas empresas no Brasil? Como se comportou a relação entre diretores-gerentes-subordinados no período de 1985 a 2011? Ocorreram mudanças no número de comandados? 0 estudo parte da perspectiva de que o perfil da estrutura de gestão e dessa relação varia de acordo com as especificidades do local onde estejam as empresas e das atividades que desenvolvem, porém, de forma geral, tem ocorrido sim uma elevação na amplitude de comando.

Com base nessa reflexão, procurou-se analisar o comportamento da ocupação em cargos de gestão e a amplitude de comando nas indústrias no período de 1985 a 2000 e de 2006 a 2011 no Brasil, em Minas Gerais e no Município de Montes Claros-MG. 0 período foi escolhido por abranger dois momentos de mudança das empresas brasileiras decorrentes da abertura econômica (década de 1990) e de retomada do crescimento do país (anos 2000).

Optou-se por fazer uma análise para o País, para o estado de MG, e para 0 município de Montes Claros-MG, visando identificar se há diferenças nos dados, para espaços geográficos diferentes. A inclusão do município de Montes Claros tem duas principais fundamentações: primeiro, a característica do seu parque industrial que, como muitos municípios do interior do país, abriga plantas industriais de médias e grandes empresas, mas com foco prioritário na produção, o que favorece a análise da relação que ora se estuda, uma vez que as principais atividades administrativofinanceiras e de suporte não são desenvolvidas nessas plantas. Segundo, é o principal município da mesorregião do Norte de Minas, que envolve 89 municípios e representa aproximadamente $22 \%$ da área geográfica de Minas Gerais (IBGE).

A cidade de Montes Claros é a maior cidade do Norte de Minas e a $6^{\mathrm{a}}$ maior do estado, centralizando indústrias, comércio, instituições de ensino (principalmente superior), serviços e órgãos públicos dessa porção de Minas Gerais. Seu parque industrial é composto principalmente por plantas industriais de médio porte de grandes empresas, com destaque para o setor têxtil, abrigando duas plantas de uma das maiores empresas do setor no Brasil.

Como fonte de dados, utilizou-se a base da Relação Anual de Informações Sociais-RAIS do Ministério do Trabalho. Foram criados indicadores que pretenderam expressar as mudanças na amplitude de comando considerando a quantidade de subordinados por chefia, para cada nível de gestão (direção e gerência).

0 artigo, além desta introdução, está organizado em mais três partes, uma considerando teoricamente 0 conceito, as origens e as mudanças na gestão, outra contendo a metodologia de coleta de dados, a terceira apresentando os resultados da análise realizada e finalmente as considerações. 


\section{A GESTÃo}

A partir do momento em que a mão de obra é livremente comercializada e 0 processo produtivo torna-se de fato capitalista, o controle assume papel essencial para obter dos trabalhadores o máximo de empenho e de produtividade, apoiado no sistema de gerência da empresa. A gestão organizacional deve ainda evitar o conflito que pode surgir nesse processo de controle e de mediação entre interesse organizacional e interesse do trabalhador (SINDEAUX, 2012, p. 43).

Braverman (1987) identifica a origem da gerência com as novas relações sociais que estavam estruturando o novo processo produtivo, no início do modo capitalista de produção. Nele, havia uma grande distinção entre quem administrava e quem executava, quem dava as ordens e quem acatava. Com o "contrato livre de trabalho", os capitalistas se viram obrigados a retirar dos trabalhadores a conduta que melhor beneficiava os seus negócios e impor sua vontade a eles, demandando a figura do gestor. Assim, para Braverman (1987, p. 68), o controle é o conceito fundamental dos sistemas gerenciais. Para ele, "Como um cavaleiro que utiliza rédeas, bridão, esporas, cenoura, chicote e adestramento desde o nascimento para impor sua vontade ao animal, o capitalista empenha-se, através da gerência (management), em controlar".

Uma das primeiras referências na análise da gerência e do controle do trabalho, na perspectiva da administração é a obra de Taylor (1979). Segundo ele, para que o trabalho possa ser realizado da melhor maneira possível, é necessário dividir adequadamente as responsabilidades entre gestão e trabalhador. Para Taylor (1979), uma chefia específica e funcional é necessária para observar se os trabalhadores entendem e aplicam as instruções repassadas aos mesmos. 0 supervisor, escolhido por seu conhecimento e habilidade pessoal na especialidade, não somente dita o que deve ser feito, mas, se preciso, ele mesmo executa a tarefa na frente do trabalhador para que sirva de exemplo de como ela deve ser realizada.

Fayol (1978), no entanto, outro clássico na análise da gerência, defende que um subordinado deve receber ordens somente de um chefe, defendendo a unidade de comando. Para ele se dois chefes exercem autoridade sobre a mesma pessoa ou sobre 0 mesmo serviço, estabelece-se uma situação de mal estar. Ou a dualidade cessa com 0 afastamento ou anulação de um dos chefes ou a organização continuará debilitada. 0 autor afirma que a dualidade de comando gera conseqüências tais como: hesitação do subalterno, perturbação, atrito de interesses opostos, aborrecimento do chefe que não foi informado, desordem no trabalho, e outras. Indo além de tal consideração, segundo Fayol (1978, p. 119), "seja qual for o seu nível hierárquico, um chefe comanda diretamente apenas reduzido número de subordinados, originalmente menos de seis. Somente o chefe (contramestre ou equivalente) comanda, às vezes, diretamente, vinte 
ou trinta homens quando a operação é simples”. Destaca também a importância do controle para que tudo permaneça "de acordo com o programa adotado, as ordens dadas e os princípios admitidos" (FAYOL, 1978, p. 130).

Mencionando os dois autores, Taylor (1979) e Fayol (1978), destaca-se a importância que tem o controle e a capacidade de obter dos trabalhadores a obediência necessária ao processo produtivo na reflexão sobre a gestão, desde os estudos clássicos. Essa importância se amplia quando ocorrem mudanças no ambiente em que estão as organizações. É o que ocorreu na década de 1990, na busca por novos modelos organizacionais e de gestão.

A partir de meados da década de 1990 no Brasil, com a abertura econômica e a economia cada vez mais integrada ao mercado internacional, as organizações passaram a buscar novas ideias no ramo administrativo e de inovarem, para que assim pudessem fazer parte da modernização que vinha ocorrendo também no mundo, com ampliação da competitividade.

Considerando as mudanças nas organizações, Mintzberg (1995), comenta que a estrutura organizacional se altera conforme 0 tamanho e a atividade das empresas e 0 ambiente na qual se insere. 0 autor menciona cinco configurações de estruturas organizacionais predominantes de acordo com o tamanho da empresa, ambiente em que se insere e atividade desenvolvida. Segundo ele, são elas: Estrutura Simples, Burocracia Mecanizada, Burocracia Profissional, Forma Divisionalizada e Adhocracia. Para Mintzberg (1995), há diferentes mecanismos de coordenação dominantes de acordo com cada configuração, variando também a área da organização que desempenha o papel mais importante e 0 tipo de descentralização implementada.

Para Benton (1977), o desenvolvimento das organizações demanda a delegação de autoridade. Para ele, à medida que uma empresa se desenvolve, torna-se claro que ninguém pode comandar eficientemente um número infinito de subordinados. Ele diz ser essencial que sejam criadas áreas separadas de atividades, tendo gerentes como responsáveis (delegação de autoridade). Os gerentes, por sua vez, também devem delegar autoridade quando se fizer necessário, de acordo com a natureza do trabalho e, também, a quantidade de subordinados para um comando eficiente.

Benton (1977) ressalta a dificuldade de comunicação conforme são criados os diversos níveis de administração e departamentos e, consequentemente, a função de controlar torna-se mais complicada. Nesse sentido, aborda o princípio do âmbito de alcance da supervisão, que consiste no número ideal de subordinados que se consegue administrar com eficiência. Uma vez que se infrinja este princípio, a probabilidade de ineficiência no âmbito da supervisão aumenta. Nessa perspectiva, os níveis hierárquicos e a amplitude de comando são inversos, ou seja, quando aqueles se elevam, a amplitude 
de comando tende a ser progressivamente menor, obedecendo à diversificação e à natureza do trabalho.

Uma mudança organizacional observada no cenário empresarial e afim à discussão da amplitude de comando é a tentativa de diminuir o tamanho das organizações e reduzir custos, juntamente com a incorporação de novas tecnologias e técnicas gerenciais, visando maior competitividade, ou o downsizing.

Segundo Dewitt (1993 apud MENDONÇA; VIEIRA, 1999), o downsizing pode ser definido como uma redução ou do capital da organização, ou dos recursos humanos, de maneira a aumentar o desempenho organizacional frente a um declínio tanto interno, quanto externo, visando corrigir qualquer desalinhamento existente. Essa redução demanda criteriosa análise pois "o foco de atenção centrado apenas no corte de pessoas e de custos é, em última análise, ineficiente para remover barreiras subjacentes à eficiência [...]" (TOMASKO, 1992 apud MENDONÇA; VIEIRA, 1999, p. 13). No entanto, muitas organizações utilizaram (e utilizam) o downsizing numa perspectiva reativa, ou seja, agindo de modo defensivo frente ao ambiente em que está inserida a organização. Assim, em um processo de downsizing, segundo Mendonça e Vieira (1999, p. 18) "algumas das estratégias mais comuns são as aquisições e desinvestimentos, os cortes no quadro gerencial, a redução no número de níveis hierárquicos e o maior uso de recompensas baseadas no desempenho".

De forma geral, as mudanças na gestão mencionadas pelos autores apontam para a redução dos níveis hierárquicos, com maior amplitude de comando e maior adequação das estruturas ao perfil da organização, ao ambiente no qual está inserida e ao corpo social que a constitui, seus trabalhadores e gestores. Assim, a análise das mudanças na composição e relação entre esse corpo social, gestores, diretores e subordinados, pode sinalizar o que efetivamente tem ocorrido nas organizações no Brasil, em Minas Gerais e na cidade de Montes Claros-MG, de acordo com as mudanças apontadas. Essa análise, com base nesses números, é o que se pretende apresentar em seguida.

\section{Metodologia}

0 foco da pesquisa é a amplitude do comando na indústria. Para analisar tal aspecto, buscou-se refletir sobre as mudanças ocorridas no número de diretores, gerentes e trabalhadores não ocupantes de cargos de gestão e a relação entre esses números, para os anos selecionados.

Dessa forma, foram criados dois indicadores que conduziram a análise: 0 Indicador Gerentes-Diretores (IGD) e o Indicador Subordinado-Gerente (ISG). 
0 IGD representa a relação entre o número de gerentes para cada diretor na indústria, denotando a amplitude de comando nesse nível de gestão. Foi obtido pela divisão do total de gerentes por empresas pelo total de diretores por empresa, o que eliminou o efeito do crescimento no número de empresas na amplitude do comando analisada. Dessa forma,

$$
I G D=\left(\frac{\Sigma G}{\Sigma E}\right) /\left(\frac{\Sigma D}{\Sigma E}\right) \text { ou } I G D=\sum G / \sum D
$$

Onde: $\quad \sum G=$ Total de Gerentes

$$
\Sigma D=\text { Total de Diretores }
$$$$
\Sigma E^{n}=\text { Total de Estabelecimentos Industriais }
$$

0 ISG apresenta a relação entre o número de trabalhadores não ocupantes de cargos de gestão para cada gerente. Esse indicador reflete a amplitude de comando para esse nível de gestão e foi obtido, assim como o indicador anterior, pela divisão do total de trabalhadores não ocupantes de cargos de gestão por empresa pelo total de gerentes por empresa, eliminando o efeito do crescimento no número de empresas na amplitude do comando analisada. Assim,

$$
I S G=\left(\frac{\Sigma s}{\Sigma E}\right) /\left(\frac{E G}{\Sigma E}\right) \text { ou IGD }=\Sigma S / \sum G
$$

Onde: $\Sigma S=$ Total de trabalhadores não ocupantes de cargos de gestão (Subordinados)

$\Sigma G=$ Total de Gerentes

$\Sigma E=$ Total de Estabelecimentos Industriais

Os dados secundários foram coletados para os anos de 1985, 1988, 1991, 1994, 1997, 2000, 2006, 2007, 2008, 2009, 2010 e 2011. Os anos de 1985 a 2000 foram utilizados para analisar historicamente o comportamento dos indicadores e verificar a 
ocorrência de mudanças em um prazo mais longo. Os dados de 2006 a 2011 demonstram o comportamento dos indicadores para os últimos anos, representando a tendência atual dos mesmos.

A fonte dos dados foi a RAIS - Relação Anual de Informações Sociais, gerenciada pelo Ministério do Trabalho e Emprego - MTE, que é uma das principais fontes de informações sobre o mercado de trabalho formal brasileiro, sendo utilizada pelo Governo na elaboração de políticas públicas de combate às desigualdades de emprego e renda, e também para a tomada de decisões dos mais diversos segmentos da sociedade (BRASIL, 2012). Os dados são disponibilizados no Programa de Disseminação de Estatísticas do Trabalho - PDET, do site do Ministério do Trabalho e Emprego.

Como a reflexão teórica possui um marco referente às empresas de maior porte e considerando que micro e pequenas empresas nem sempre possuem estrutura organizacional formalmente definida, optou-se por trabalhar com os dados de empresas acima de 100 empregados, caracterizadas como médias e grandes empresas.

Para a classificação dos cargos de gestão utilizou-se a Classificação Brasileira de Ocupações - CB0. Para os anos de 1985, 88, 91, 94, 97 e 2000, foi considerada a CB0 94 e para os anos a partir de 2006, a CBO 2002. Os dados foram coletados para o município de Montes Claros-MG, o estado de Minas Gerais e para o Brasil, proporcionando comparações entre os três níveis geográficos.

\section{RESULTADOS E DISCUSSÃO}

Conforme mencionado, a análise realizada diferencia gestores e subordinados. Entre os gestores, há ainda uma diferenciação entre diretores e gerentes. Inicialmente são descritas as variações na quantidade de gestores e subordinados no período para, posteriormente, serem comentadas as mudanças na relação entre o número de gestores e de subordinados, destacando o aspecto da amplitude de comando.

\section{MUDANÇAS NA QUANTIDADE DE GESTORES NO PERÍODO}

\section{OS GERENTES}

As variações ocorridas na quantidade de gestores no período são apresentadas no Gráfico 1. É possível observar que no município de Montes Claros, as mudanças na quantidade de Gerentes no setor industrial oscilam muito de ano para ano. Percebe-se que a partir de 1991 há um declínio dessa quantidade, chegando a cair aproximadamente à metade $(53,2 \%)$ até 2006 . Depois desse declínio, ocorre uma variação positiva de 1,55, entre 2006 e 2007, no qual houve um aumento de 45,45\% do número de Gerentes. Ao longo dos anos estudados, tem-se uma variação média de 1,03. 
Observa-se também que para Minas Gerais, o comportamento dessas oscilações segue o mesmo padrão da variação percebida no município de Montes Claros, havendo um grande declínio $(71,93 \%)$ na quantidade de Gerentes entre os anos 2000 a 2006 para logo em seguida, entre os anos de 2006 e 2007 haver crescimento do número de gerentes, voltando ao patamar anterior à década de 2000. 0 ano de 2011 se encerra com um aumento de aproximadamente 3 (três) vezes no número desses trabalhadores, se comparado com 2010, ano anterior.

Gráfico 1 - Variação anual do número de Gerentes do Setor Industrial

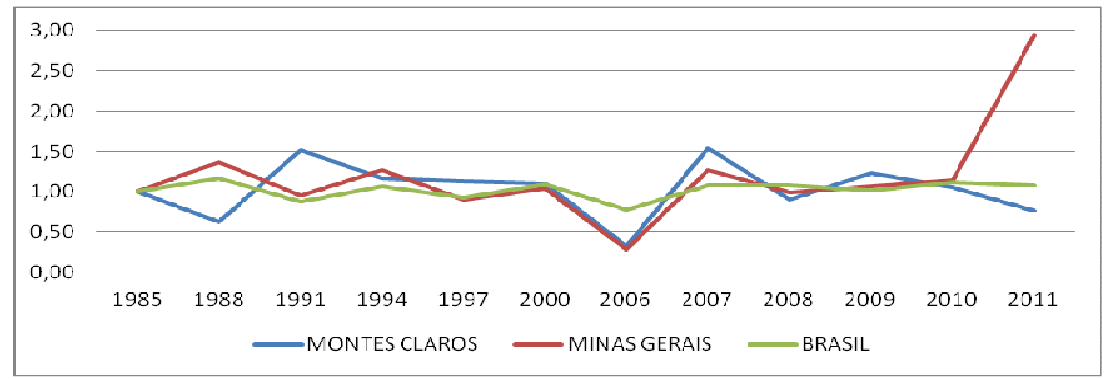

Obs.: $1985=1$

Fonte: Elaboração própria a partir da RAIS/MTE

Quanto à análise em nível de Brasil, percebe-se uma pequena variação anual da quantidade de gerentes, tendo essa variação uma média de 1,02 mostrando que a oscilação não foi tão grande. A Quantidade de Gerentes do setor industrial no ano de 1985 era de 70.503 trabalhadores e, no último ano analisado (2011), encontra-se um total de 85.072 Gerentes, significando um aumento de 20,66\%.

\section{OS DIRETORES}

A quantidade de Diretores em Montes Claros ao longo dos anos analisados se comporta de maneira praticamente inversa ao que ocorre nos níveis estadual e nacional, conforme pode ser observado no Gráfico 2. É possível verificar que até a década de 1990 ocorreu uma elevação do número de Diretores das indústrias de Montes claros, crescimento esse que cai 31,57\% se comparado o período de 1991 a 2000. É interessante destacar o declínio da quantidade de Diretores em Montes Claros ao longo dos anos analisados, que se estabiliza a partir de 2009, permanecendo sem variação até 0 ano de 2011. 
No estado de Minas Gerais, a variação da quantidade dos Diretores de indústrias é muito significativa e, a partir de 2000 até 2006 há uma queda de 53,6\% na sua quantidade. Há uma variação positiva de 1,07 de 2006 para 2007, mas não suficiente para retornar à quantidade de Diretores do patamar anterior à década de 2000. Fugindo ao comportamento do período, assim como no caso dos gerentes (Gráfico 1), o ano de 2011 é marcado por uma grande ampliação da quantidade de Diretores, com aumento de 216,88\%, variando 3,17 vezes em relação ao ano de 2010.

Gráfico 2 - Variação Anual do número de Diretores do Setor Industrial

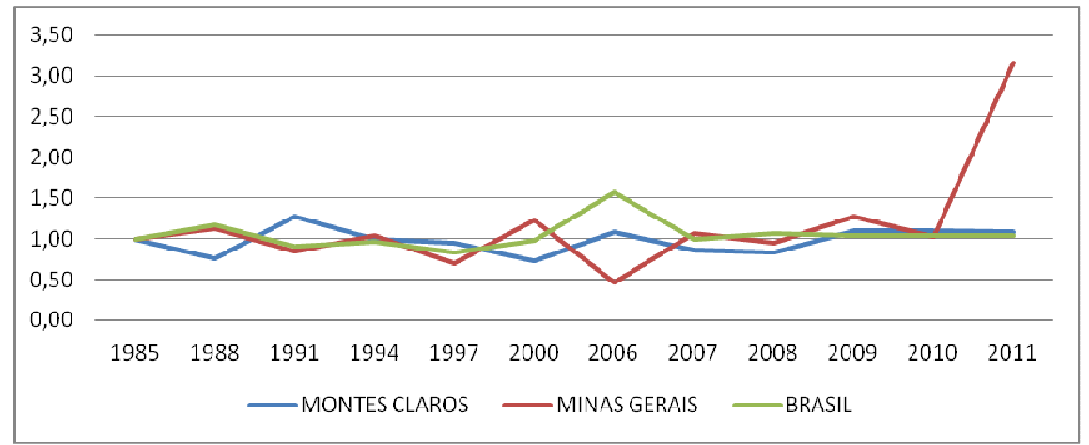

Obs.: $1985=1$

Fonte: Elaboração própria a partir da RAIS/MTE

No caso do Brasil, a variação da quantidade de Diretores é pequena, com média de 1,05 ao longo dos 12 anos analisados. Uma situação que merece destaque é o movimento inverso que ocorre no Brasil e, no mesmo período de análise, no estado de Minas Gerais. Entre os anos 2000 e 2006 houve uma variação positiva de 1,57 no Brasil (a maior ao longo de todo o período) e, como mencionado, uma queda de 53,5\% em Minas Gerais. Após 2006, há uma estabilização da quantidade dos Diretores no Brasil até 0 ano de 2011, também diferente do comportamento em Minas Gerais e semelhante ao que ocorre em Montes Claros.

\section{MUDANÇAS NA QUANTIDADE DE SUBORDINADOS NO PERÍODO}

Os trabalhadores aqui denominados "Subordinados" são aqueles que não exercem cargos de diretoria, gerencia e/ou supervisão. 0 Gráfico 4 apresenta a variação da quantidade desses trabalhadores para o período selecionado. 
Analisando a situação para Montes Claros, é possível perceber que a variação anual dessa quantidade se deu de forma moderada, com média de 1,03 para o período, demonstrando não haver mudanças bruscas na quantidade de Subordinados de ano para ano. Embora a variação tenha sido pequena, houve até o ano de 1997 um crescimento considerável, atingindo 7.751 trabalhadores nesse ano, aumento de 87,63\% se comparado com 1985, primeiro ano analisado. A variação anual da quantidade de Subordinados de 1994 a 1997 foi de 1,18, caindo para 0,81 de 1997 a 2000. Deste ponto em diante, a quantidade de subordinados volta a crescer, mas não atinge a quantidade existente em 1997, que foi a maior para o período. No ano de 2011, o total de subordinados nas indústrias de Montes Claros chegou a 5.241 trabalhadores.

Gráfico 4 - Variação Anual da quantidade de Subordinados do Setor Industrial

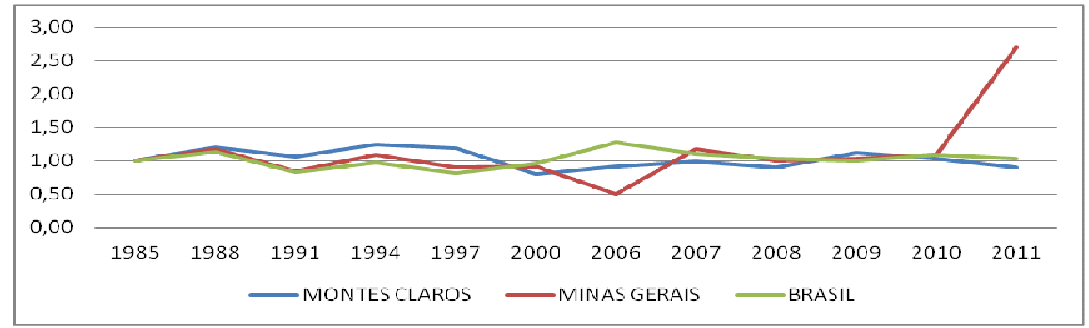

Obs.: $1985=1$

Fonte: Elaboração própria a partir da RAIS/TEM.

Em Minas Gerais, a variação anual da quantidade de Subordinados se mostra maior em alguns anos. A média dessa variação foi de 1,12, maior que a variação média em Montes Claros. A quantidade de Subordinados em Minas Gerais oscila até o ano de 1994 quando então, entra em decréscimo até 0 ano de 2008, chegando a cair 58,86\% no ano de 2006 em relação a 2005. É interessante ressaltar que, embora a variação da quantidade de Subordinados de 2006 a 2007 seja relevante (1,17), o crescimento da quantidade ao longo dos anos continua pequeno, com aumento de apenas $6,88 \%{ }^{4}$.

A variação anual da quantidade de Subordinados nas indústrias brasileiras foi pequena no período, com média de 1,02 por ano. Nota-se que a quantidade desses trabalhadores cresce no início do período, aumentando 12,86\% de 1985 a 1988, mas decresce continuamente por toda a década de 2000 , chegando a cair $35,72 \%$ se

\footnotetext{
${ }^{4} 0$ efeito causado na curva do gráfico (gráfico 4) é justificado pelo fato que 0 ano de 2006 foi 0 pico negativo da curva. Assim, uma pequena alteração na quantidade de subordinados em 2007 é suficiente para elevar 0 índice da variação da quantidade.
} 
comparado com o ano de 1988. A maior variação anual da quantidade ocorre em 2006, quando recomeça o crescimento do número de Subordinados nas indústrias brasileiras.

0 Quadro 1 apresenta uma síntese das mudanças no número de diretores, gerentes e subordinados, para os três níveis geográficos.

Quadro1 - Síntese na variação na quantidade de gestores e subordinados.

\begin{tabular}{|c|c|c|c|}
\hline \multicolumn{4}{|c|}{ VARIAÇÃO NA QUANTIDADE DE GESTORES E SUBORDINADOS } \\
\hline & Diretores & Gerentes & Subordinados \\
\hline $\begin{array}{c}\text { Montes } \\
\text { Claros }\end{array}$ & $\begin{array}{l}1991 \text { a } 2000 \text { queda de } \\
31,57 \% \text {. } \\
\text { A partir de } 2009 \text { o número se } \\
\text { estabiliza permanecendo sem } \\
\text { variação. }\end{array}$ & $\begin{array}{c}\text { Grande oscilação. } \\
1991 \text { - declínio 53,2\% } \\
2006 \text { - aumento } \\
\text { 45,45\% }\end{array}$ & $\begin{array}{c}\text { Não houve mudanças bruscas } \\
\text { de ano p/ ano. } \\
1985-4.131 \\
2011-5241\end{array}$ \\
\hline $\begin{array}{l}\text { Minas } \\
\text { Gerais }\end{array}$ & $\begin{array}{l}\text { Variação significativa. } \\
2000 \text { a } 2006 \text { queda de 53,6\%. } \\
2006 \text { a } 2007 \text { variação } \\
\text { positiva de } 1,07 . \\
2011 \text { aumento de } 217 \%\end{array}$ & $\begin{array}{c}\text { Semelhante ao } \\
\text { município. } \\
\text { Mas } 2011 \text { cresce } 3 \text { vezes } \\
\text { mais que em } 2010\end{array}$ & $\begin{array}{l}\text { Variação média de } 1,12 \text {. } \\
2006 \text { cai cerca de } 59 \% \text {. } \\
\text { A partir de } 2007 \text { cresce } \\
\text { novamente. } \\
\text { Crescimento pequeno ao longo } \\
\text { doa anos. }\end{array}$ \\
\hline Brasil & $\begin{array}{c}\text { Variação pequena (1,05 ao } \\
\text { longo dos } 12 \text { anos). } \\
2000 \text { a } 2006 \text { variação } \\
\text { positiva de } 1,57 . \\
2006 \text { cai, e se matem a } \\
\text { partir de } 2007\end{array}$ & $\begin{array}{l}\text { Pequena variação } \\
\text { anual }(1,02) . \\
\text { Entre } 1985 \text { e } 2011- \\
\text { aumento de } 20,66 \%\end{array}$ & $\begin{array}{l}\text { Variação pequena. Média de } \\
1,02 \text { por ano. } \\
\text { Até } 1988 \text { o nº cresce, diminui } \\
\text { até } 2006 \text { onde recomeça o } \\
\text { crescimento. }\end{array}$ \\
\hline
\end{tabular}

Fonte: Elaboração própria a partir dos dados da RAIS/MTE

\section{MUdANÇAS NA AMPLITUDE DE COMANDO: A RELAÇÃo GERENTES/DIRETORES - IGD}

0 Comportamento das quantidades dos Gerentes e Diretores das indústrias em Montes Claros, no estado de Minas Gerais e no Brasil também está relacionado à amplitude de comando nessas indústrias e, por isso, será analisado conforme os indicadores definidos na metodologia (item 3). 0 Gráfico 3 apresenta o comportamento do IGD para o período.

Percebe-se em linhas gerais que o comportamento da relação Gerentes/Diretores nos três níveis geográficos é semelhante (Gráfico 3). Em Montes Claros, a quantidade 
média de Gerentes sob o controle de um Diretor ao longo dos anos estudados foi de 5,84 $(\mathrm{IGD}=5,84)$.

Gráfico 3 - Comportamento do IGD nos anos selecionados.

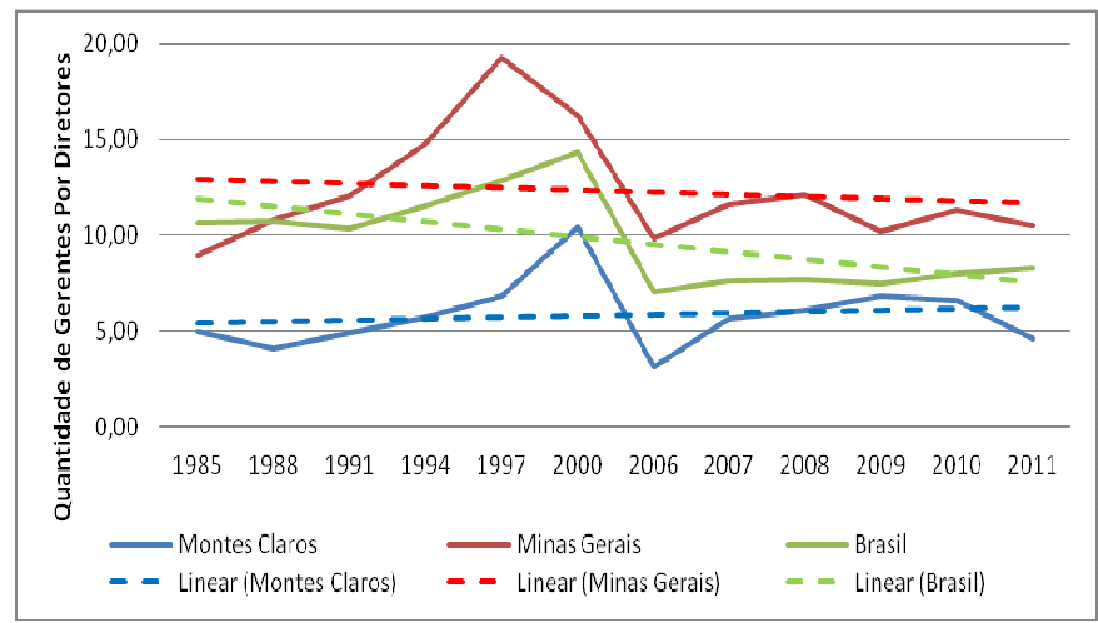

Fonte: Elaboração própria a partir da RAIS/MTE

A análise mais detalhada dessa relação em Montes Claros demonstra que nos anos que precedem a década de 1990 há uma queda no número gerentes/diretores, embora não tão relevante quanto o aumento que se tem a partir desta data. Analisando os anos de 1988 a 2000 observa-se um crescimento do IGD de 4,13 no referido ano para 10,46 em 2000. Isso se deve ao aumento do número dos gerentes em maior intensidade do que no número de diretores, conforme mencionado na análise anterior (item 3.1). Ocorreu, dessa forma, um aumento do número de Gerentes para um mesmo Diretor nesse período.

Do ano de 2006 para 2007, a situação se inverte e o IGD cai para 3,14 como reflexo da alteração da quantidade de Gerentes cuja variação $(0,32)$ foi menor do que aquela ocorrida no número de Diretores $(1,08)$. De forma geral, observa-se uma tendência linear de crescimento do IGD nas indústrias de Montes Claros no período, embora nos últimos anos (a partir de 2009) tal tendência tenha se invertido.

A maior relação entre Gerentes e Diretores acontece em Minas Gerais. A média de Gerentes por Diretores ao longo dos 12 anos de estudo é de 12,31 (IGD=12,31), sendo 
maior que a relação em Montes Claros $(\mathrm{IGD}=5,84)$ e no Brasil $(\mathrm{IGD}=9,72)$. Observa-se um crescimento elevado da quantidade de Gerentes sob o controle de um mesmo Diretor até 0 ano de 1997, onde a relação atinge seu pico, com IDG=19,26. Há um pico negativo no ano de 2006, com o indicador caindo 48,90\% em relação ao ano de maior índice (1997). A tendência apontada para o período é de queda no IGD em Minas Gerais embora, diferente do que ocorreu em Montes Claros, nos últimos anos (a partir de 2009) tenha havido um crescimento no indicador.

0 comportamento do indicador em nível de Brasil foi semelhante aos supracitados durante o período, embora na maioria dos anos analisados o IGD se posicione em valores intermediários: nem baixos como os de Montes Claros, nem altos como os encontrados no estado de Minas Gerais.

Analisando o período, destaca-se o ano 2000, quando o IGD chega a 14,34 Gerentes por Diretores, maior valor da série analisada. Nos anos seguintes, assim como nos outros níveis geográficos, houve uma queda do número de Gerentes em relação aos Diretores. No Brasil a variação da quantidade de Gerentes de 2000 a 2006 foi de apenas 0,77 (Gráfico 1), e na quantidade de Diretores foi de 1,57 (Gráfico 2), justificando a queda do IGD. Observa-se que assim como para Minas Gerais, há uma tendência de diminuição do número de Gerentes/Diretores no setor industrial brasileiro, embora sem a indicação de mudança dessa tendência nos últimos anos.

Percebe-se então que o comportamento da relação Gerentes/Diretores em Montes Claros, Minas Gerais e no Brasil, de forma geral, é semelhante. Nos três casos há um crescimento do IGD começando no ano de 1985 e indo até aproximadamente a década de 2000. Os anos que seguem até 2006 foram marcados pela queda dessa relação, diminuindo dessa forma a amplitude de comando dos Diretores sobre os Gerentes das indústrias nos três âmbitos. Existe, após esse ano, um novo crescimento, porém 0 indicador permanece em um "patamar" inferior à situação existente antes do declínio. Montes Claros apresenta os menores valores do indicador em todo o período, abaixo da média brasileira enquanto Minas Gerais possui níveis acima da média do Brasil.

\section{MUDANÇAS NA AMPLITUDE DE COMANDO: A RELAÇÃO SUBORDINADOS/GERENTES - ISG}

0 Gráfico 5 apresenta o comportamento do ISG para o período analisado, demonstrando as mudanças no número de subordinados por gerentes em Montes Claros, Minas Gerais e Brasil.

Tendo como foco Montes Claros, podemos perceber que houve grande variação no período, embora mantendo a tendência de crescimento do indicador e, consequentemente, de elevação da amplitude de comando nesse nível. No período 
merecem destaque os anos de 1988, 2000 e 2006, que apresentam variações maiores no indicador, considerando a tendência mencionada. Dos três anos citados, o ano 2000 se destaca por apresentar variação negativa com relação ao período anterior. De forma geral, o aumento da relação subordinados por gerente no período tem destaque no ano de 2006 que, além de apresentar o maior valor do indicador $(\mathrm{ISG}=129,66)$ representa uma mudança no seu patamar para valores acima de 73 subordinados por gerente, valor maior do que a média de Minas Gerais e do Brasil.

\section{Gráfico 5-Comportamento do ISG nos anos selecionados}

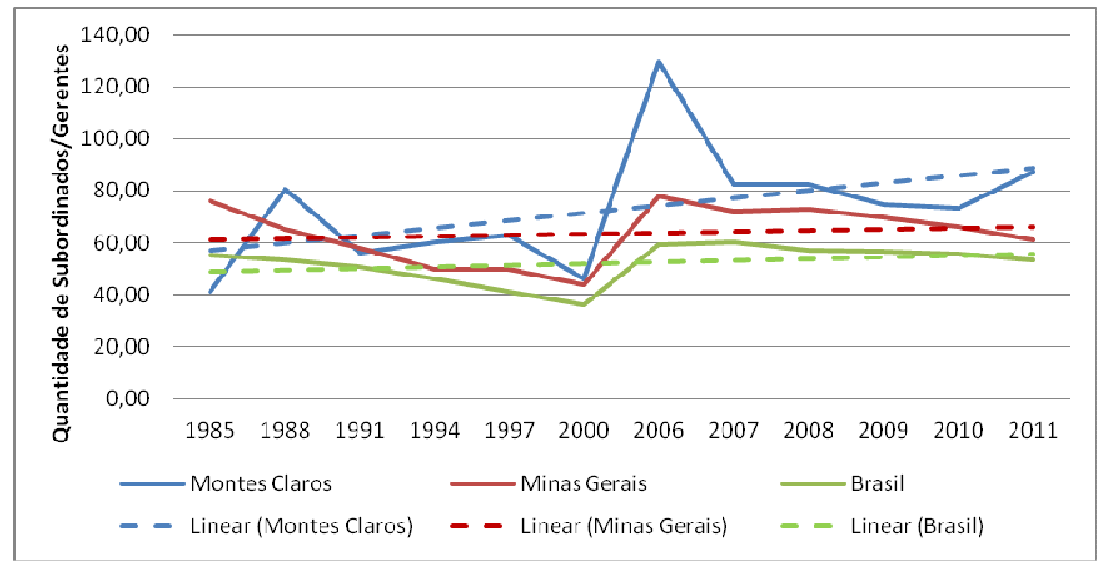

Fonte: Elaboração própria a partir da RAIS/MTE

Com relação a Minas Gerais, o Gráfico 5 aponta uma tendência de estabilização do ISG em níveis próximos, porém abaixo de 70 subordinados por gerente, embora seja possível observar dois períodos distintos na série selecionada. Um ocorre de 1985 até 0 ano 2000, com redução do IGS ao menor nível de todo o período $(43,78)$ e outro a partir de 2006, (pico máximo do indicador para o estado: 77,77), com mudança no patamar do indicador para níveis acima de 60. 0 IGS em Minas Gerais possui valores menores do que aqueles apresentados em Montes Claros, ou seja, os gerentes desse município comandam cerca de 10 subordinados a mais do que a média dos gerentes em Minas Gerais.

Quando o nível de análise é o Brasil, os dados demonstram um comportamento do ISG semelhante ao que ocorre em Minas Gerais, porém com valores diferentes e em escala inferior. 0 valor médio do IGS para o período no Brasil foi de 54 subordinados por gerente, com pico também em 2006, de 59,66, valor inferior ao encontrado em Minas Gerais e Montes Claros. 
Comparando o indicador dos três níveis geográficos, percebe-se que Brasil e Minas Gerais seguem uma tendência semelhante de redução da relação subordinados por gerente e, consequentemente de amplitude de comando; enquanto em Montes Claros a tendência é inversa, de aumento dessa amplitude.

\section{CONSIDERAÇÕES FINAIS}

0 artigo buscou analisar, a partir de dados sobre a quantidade de diretores, gerentes e subordinados, a amplitude de comando nas empresas industriais brasileiras, mineiras e de Montes Claros.

Buscou-se refletir enquanto teoria sobre a necessidade de controle e gestão por parte das empresas, principalmente a partir do momento em que elas passam a ter uma estrutura mais complexa, melhor elaborada. Discutiu-se ainda que as mudanças ocorridas na sociedade e no mercado têm influenciado as organizações e sua estrutura de comando e gestão. Ressaltou-se que os diferentes modos de controle variam de acordo com o tipo de estrutura organizacional predominante na empresa e com a maior ou menor necessidade de delegação de poder, considerando a dificuldade de uma única pessoa controlar um número muito grande de subordinados.

Tais mudanças e dinâmica das organizações têm alterado a sua estrutura, que tende a sofrer um achatamento, visando a redução de custos e de pessoal, num processo denominado Downsizing, muito difundido no início da década de 1990. Com isso, segundo a reflexão realizada, há uma diminuição dos níveis hierárquicos, aumentando consequentemente a amplitude de comando.

Partindo dos dados coletados da base RAIS do MTE, foram desenvolvidos dois indicadores (IGD e ISG) para melhor mensuração e visualização do comportamento da amplitude de comando nas empresas industriais com mais de 100 empregados em Montes Claros, Minas Gerais e Brasil.

Os resultados apontaram que, no que tange ao IGD, o comportamento em Montes Claros, Minas Gerais e no Brasil, se assemelham. Nos três casos há um crescimento da quantidade de Gerentes para cada Diretor a partir do primeiro ano analisado até o fim da década de 1990, aumentando a amplitude de comando dos Diretores. É possível sugerir, embora com ressalvas e necessitando de maior aprofundamento, que este aumento tenha ocorrido seguindo as proposições das "teorias" de mudanças da estrutura organizacional que defendem 0 achatamento vertical, aumentando dessa forma a quantidade de controlados para um único controlador, resultando em maior amplitude de comando.

Os anos que seguem até meados dos anos 2000 foram marcados pela queda dessa relação, diminuindo dessa forma a amplitude de comando dos Diretores sobre os 
Gerentes das indústrias nos três níveis geográficos, contrariando a perspectiva do downsizing.

Junto a este fator, a crise da década de 1980 e 1990 pode ter levado as empresas a modificarem suas estruturas organizacionais, reduzindo o número de diretores pouco afins à produção e mantendo os profissionais de gestão de cunho mais operacional, mantendo o número de gerentes, que são capazes de desempenhar as funções sem tanto prejuízo das atividades.

Assim, a amplitude de comando aumentou ao longo daqueles anos, não devido ao aumento da quantidade de gerentes, mas sim à redução da quantidade dos diretores, que, readmitidos posteriormente, fez o IGD crescer até início da década de 2000.

Nos anos seguintes ocorre, em Montes Claros, Minas Gerais e no Brasil, uma queda do número de gerentes do ano de 2000 a 2006, que se mostra contrária em relação aos diretores, o que pode indicar o retorno das estruturas industriais à sua distribuição inicial verticalizada, onde o número de diretores era consideravelmente alto, diminuindo a quantidade de gerentes sob o seu domínio. Essa diminuição do IGD pode indicar a melhoria das condições de estabilidade econômica e consequente retomada das estruturas organizacionais ou ainda o desuso das técnicas de downsizing nestas indústrias. Embora haja períodos de crescimento do indicador após 2006, a relação Gerentes/diretores permanece em um "patamar" inferior à situação existente antes do declínio, se assemelhando cada vez mais com a situação inicial observada em 1985.

Em Montes Claros, a tendência da amplitude de comando dos diretores em relação aos gerentes nas indústrias é de aumento, mesmo com IGD caindo ao longo dos últimos anos. Isso pode sugerir que as empresas locais ainda não estabilizaram sua relação entre diretores e gerentes, abalada pelas situações aqui mencionadas sobre as condições de mercado e economia, sendo o crescimento dos diretores pequeno em relação ao crescimento da quantidade de gerentes.

Já nos outros níveis estudados, tanto em Minas Gerais, quanto no Brasil, a tendência do IGD é de queda, o que pode ser entendido como uma preservação dos gerentes e uma movimentação das quantidades de diretores, entendendo ser 0 gerente peça fundamental para o bom funcionamento das indústrias.

Em relação ao ISG, a análise mostra uma situação inversa ao que acontece com o IGD. Tem-se que os três níveis geográficos estudados seguem uma tendência semelhante no período analisado. De 1985 ao início dos anos 2000, Minas Gerais e Brasil enfrentam uma diminuição da amplitude de comando no setor industrial, visto que 0 número de subordinados diminui e o número de gerentes sofre um moderado crescimento. Montes Claros, no entanto, mantem sua amplitude de comando semelhante ao primeiro ano analisado, uma vez que as variações, tanto de gerentes 
como de subordinados, ocorreram de maneira semelhante. Esse decréscimo ao nível de país e estado pode ter sido ocasionado pelo período de retração da economia nacional e global, desde a década de 80, e as demissões de funcionários decorrentes da mesma. Assim sendo, um menor número de subordinados, contribui para uma menor amplitude de comando dentro das indústrias, se os níveis superiores são preservados.

Entre 2000 e 2006, os índices apresentam uma considerável elevação, mostrando um aumento da amplitude de comando. Montes Claros se destaca, visto que seus índices são os maiores dentre os analisados. Minas Gerais e Brasil também sofrem uma elevação, mas com números mais discretos em relação ao município. De 2006 a 2007, 0 índice volta a sofrer uma queda nos três níveis geográficos estudados.

A partir de 2006, o indicador cresce em relação aos anos anteriores, mas as variações para Minas Gerais e Brasil tornam-se menores e a amplitude de comando nesse caso, parece estabilizar. Em Montes Claros, no entanto, há uma elevação no número de subordinados, enquanto que o número de gerentes sofre uma queda, provocando o crescimento do ISG. Tal aspecto pode estar relacionado ao perfil da indústria local, que sendo em sua maioria constituída de plantas de produção, tem sua capacidade produtiva ampliada sem necessariamente ampliar a estrutura organizacional. Por outro lado, pode sugerir também que os subordinados na cidade sejam de mais fácil controle, possibilitando a um gerente comandar maior número de subordinados. Em ambos os casos, o aprofundamento da questão merece estudos mais detalhados que fogem, no momento, ao escopo deste trabalho.

De forma geral, da análise realizada é possível destacar três aspectos: primeiro, embora os resultados obtidos tenham demonstrado não haver significante variação na amplitude de comando na relação entre Gerentes/Diretores ao longo do período estudado, a relação Subordinados/Gerentes apresentou crescimento. Assim, foi possível identificar um padrão de comportamento semelhante nos três níveis geográficos, para ambos os indicadores. Dessa forma, a perspectiva inicial de que haveria uma tendência de aumento na amplitude de comando parece ter sido confirmada, para o nível gerentesubordinado, o que não ocorreu para o nível diretores-gerentes, com pequena tendência de queda. Conforme mencionado, isso pode estar ocorrendo devido a questões de expansão ou retração da economia, ou ainda decorrente de alterações no modelo organizacional das empresas, com mudanças nas funções de gerência e direção. A análise dessas questões merece novas pesquisas.

0 segundo aspecto de destaque é a diferença na amplitude de comando entre os níveis de diretoria e de gerência. Enquanto um diretor é responsável em média por 9,72 gerentes no Brasil, um gerente responde por 54 subordinados, ou seja, quase 6 vezes mais que um diretor. Essa situação pode denotar uma característica de centralização de comando nos níveis mais elevados, que pode ser resultado das mudanças nas estruturas 
organizacionais, por um lado ou, ainda, manutenção de características tradicionais de centralização de poder ainda persistentes nas empresas de estruturas mais tradicionais. Tais questões também merecem aprofundamento.

0 terceiro destaque quanto aos resultados diz respeito às diferenças no comportamento dos indicadores para o Brasil, Minas Gerais e Montes Claros. Embora a análise tenha sido simplesmente descritiva, os resultados sugerem diferenças importantes entre os níveis geográficos, o que pode reforçar a perspectiva de que as organizações possuem estruturas diferentes em espaços geográficos diferentes, com destaque para a questão do município, nesse caso Montes Claros, interior de Minas Gerais. Analisar a questão para outros municípios e outros estados da federação pode contribuir para reforçar (ou não) a perspectiva da existência de diferenças regionais. No entanto, de forma geral, os resultados tendem a reforçar a reflexão teórica de que a gestão nas empresas tem mudado e que essas mudanças seguem de perto o ambiente no qual a organização está inserida, com comportamento diferente para diferentes espaços.

\section{REFERÊNCIAS}

BENTON, Lewis R. Supervisão e gerência. Rio de Janeiro: Zahar, 1977.

BRAVERMAN, Harry. Trabalho e capital monopolista. 3. ed. Rio de Janeiro: LTC, 1987.

BRASIL. Ministério do Trabaho e Emprego - TEM. Relação anaula de informações Sociais. disponível em: < http://portal.mte.gov.br/rais/> Acesso em: 14 ago. 2012.

FAYOL, Henri. Administração industrial e geral. 9. ed. São Paulo: Atlas, 1978.

MENDONÇA, José Ricardo Costa de; VIEIRA, Marcelo Milano Falcão. Fundamentos para análise do downsizing como estratégia de mudança organizacional. Revista Eletrônica de Administração, Porto Alegre, v. 5, n. 3, p. 12, 1999. Disponível em: $<$ http://www.lume.ufrgs.br/bitstream/handle/10183/19414/000301441f>. Acesso em: 14 ago. 2012.

MINTZBERG, Henry. Criando organizações eficazes: estruturas em cinco configurações. São Paulo: Atlas, 1995.

SINDEAUX, Roney Versiani. Mercado de trabalho e controle do processo de trabalho na indústria: um estudo no Norte de Minas. 2012. 299 f. Tese (Doutorado em Economia) - Universidade Federal de Minas Gerais, 2012.

TAYLOR, Frederick W. Princípios da administração científica. 7. ed. São Paulo: Atlas, 1979 . 